\title{
The ethics of memory blunting: some initial thoughts
}

\section{Erik Parens*}

Bioethics, The Hastings Center, Garrison, NY, USA

${ }^{*}$ Correspondence: parense@thehastingscenter.org

\section{A commentary on}

Toward a new treatment for traumatic memories.

by Debiec, J., and Altemus, M. (2006). Cerebrum 1-11.

The ability to interrupt memory reconsolidation and thereby blunt the intensity of emotions associated with painful memories raises the ethical question, Should there to be a limit on efforts to manipulate our memories? (Debiec and Altemus, 2006). The answer is yes - but with important qualifications.

We in the West have long contemplated what it would mean, not just to blunt the emotional intensity of some memories, but to erase them altogether. Homer sang of Odysseus's visit to a land whose inhabitants ate mythical Lotus flowers, which made his men forget everything they ever knew (President's Council on Bioethics, 2003).As Tennyson much later retold it, Odysseus's men became blissfully happy to "lie reclined on the hills like gods ..., careless of mankind." In erasing their memories, the Lotus flowers also erased the men's desire to engage in human actions and relationships, and thus made them inhuman.

So, insofar as having a human self requires having memories, and insofar as erasing all of them would be tantamount to annihilating one's self (Wasserman, 2004; Levy, 2007), we can glimpse a first point of easy agreement. No matter how enthusiastic we might generally be about using new technologies to shape ourselves, none of us would sign on for complete memory erasure; none of us wants to become inhuman.

If we picture memory erasure as being on the left end of a continuum, which stretches from highly undesirable forms of memory manipulation on the left to highly desirable forms on the right, then just a bit to the right of memory erasure would be some forms of memory blunting that many could readily agree would also be undesirable. Imagine, e.g., that a pharmaceutical company cre- ates a drug that promises to relieve the suffering of people haunted my memories of being humiliated in their workplace (Henry et al., 2007).

We might worry that the pharmaceutical company cared more about profit than consumers' well-being. Or we might worry that treating a non-medical problem (the suffering associated with being humiliated) as a medical problem (in need of drug treatment) is a "category mistake" - and thus bad in itself. I submit, however, that scenarios like this one bring to the surface another, even more fundamental objection: that it is bad to separate someone from her proportionate response to a difficult but normal human experience. If someone who was humiliated did not feel humiliated, we would worry that something was terribly amiss. In general, we think that, rather than attempt to blunt the intensity of such a proportionate response, we should endure it and perhaps act on it - either by exiting the situation or changing it. None of us would endorse a drug "treatment" that threatened to alienate us from our experience of how we and the world truly are.

If easy agreement about the badness of a hypothetical pill for total memory erasure is at the left tail of the continuum, then at the right tail is equally easy agreement about the goodness of a hypothetical pill that would, for example, vaccinate soldiers against PTSD. The justification for this vaccination would be the same as for any other. We seek to prevent the onset of disorders because, by definition, they impair a person's ability to flourish; they cut one off from one's opportunity to engage with the world as it is. The vaccine would presumably insure that, when we laid down new memories, future opportunities for reconsolidation would elicit only responses that were proportional to the trigger; it would not erase traumatic memories nor alienate us from our experience of how we and the world truly are.

And on the continuum just to the left of the vaccine there will be ready agreement about the goodness of treating PTSD. Even the hardest-nosed critics of pharmacological self-shaping, such as the Presidential Bioethics Council, endorse using drugs to blunt the sting of memories when the intensity of those memories is disproportionate to their cause and is impairing. As the Council acknowledges, traumatic memories associated with severe PTSD cast "a shadow over one's whole life, making the pursuit of happiness impossible." (President's Council on Bioethics, 2003, p. 220). Like any medical treatment, memory blunting in this context would promote an individual's ability to engage in the sorts of activities and relationships that human beings need to flourish.

Does this mean there will be no disagreement about the ethics of interrupting memory reconsolidation? No. Inevitably, there is a zone of ambiguity in which reasonable people, due to differences in value commitments, will reach different conclusions about whether the intensity of a given person's emotional responses are proportional to their trigger. In addition to reasonable differences, some observers will make mistakes, by either wildly underor over-estimating the proportionality of a given individual's response. But neither the problem of legitimate value differences nor the problem of mistaken readings of the facts is unique to this context. Across the board in medicine, particularly in psychiatry, patients, families, and clinicians have to deal with the zone of ambiguity, bordered on one side by cases where intervention is ethically required and on the other by cases where not intervening is required.

So, we can imagine some interventions that would be beyond any reasonable ethical limit. We can agree, e.g., that it would be inappropriate to blunt emotional responses that are proportionate to a trigger (as with the humiliated office worker). And we can agree that some interventions are ethically required, e.g., when the intensity of an emotional response is disproportionate to its trigger (as occurs with PTSD). And 
perhaps by now we can agree that there will be a zone of ambiguity on the continuum between the region on the left where not intervening is called for and the region on the right where it is called for. Because that zone of ambiguity will be substantial, and because the chances of drawing public policy lines that are both clear and fair will therefore be slim, it may be best to leave decisions in the zone of ambiguity to patients and clinicians who are committed to making truly informed decisions.

\section{REFERENCES}

Debiec, J., and Altemus, M. (2006). Toward a new treatment for traumatic memories. Cerebrum $1-11$.

Henry, M., Fishman, J. R., and Youngner, S. J. (2007). Propranolol and the prevention of post-traumatic stress disorder: is it wrong to erase the "sting" of bad memories? Am. J. Bioeth. 7, 12-20.

Levy, N. (2007). Neuroethics: Challenges for the 21st Century. New York: Cambridge University Press, 171-172.

President's Council on Bioethics. (2003). Beyond Therapy: Biotechnology and the Pursuit of Happiness. New York, NY: Regan Books.
Wasserman, D. (2004). Making memory lose its sting. Philos. Public Policy Q. 24, 12-18.

Received: 06 December 2010; accepted: 06 December 2010; published online: 20 December 2010.

Citation: Parens E (2010) The ethics of memory blunting: some initial thoughts. Front. Behav. Neurosci. 4:190. doi 10.3389/fnbeh.2010.00190

Copyright (c) 2010 Parens. This is an open-access article subject to an exclusive license agreement between the authors and the Frontiers Research Foundation, which permits unrestricted use, distribution, and reproduction in any medium, provided the original authors and source are credited. 